\title{
PROJETO DE EXTENSÃO SOBRE A SEGURANÇA DA NAVEGAÇÃO E A PREVENÇÃO DE ACIDENTES NA PESCA ARTESANAL
}

Eduardo Antonio Temponi Lebre

Universidade Federal de Santa Catarina- UFSC eat167@terra.com.br

Miguel João Schmitz Junior Força Aérea Brasileira - FAB miguel_schmitz@hotmail.com

Renato Miranda Carvalho

Universidade Federal de Santa Catarina- UFSC renatomcarvalho@yahoo.com.br

Erro! Fonte de referência não encontrada.

A pesca artesanal no Brasil apresenta limitadas condições de expansão pela falta de políticas públicas, atuando em poucos quilômetros da costa com poucos recursos navegacionais e grandes riscos de acidentes. A pesca artesanal é a praticada diretamente por pescador profissional, de forma autônoma ou em regime de economia familiar, com meios de produção próprios ou mediante contrato de parceria, utilizando embarcações de pequeno porte. Os riscos que acometem os pescadores artesanais são provenientes de diversos âmbitos, inclusive por trabalho excessivo, destacando-se os riscos naturais, químicos e físicos, estando sujeitos às condições do mar e da embarcação. Por estes motivos, o Núcleo AQUASEG da Universidade Federal de Santa Catarina (UFSC) promove a capacitação na área do cumprimento das normas de segurança da navegação e a aplicação do conhecimento de novas tecnologias para prevenção de naufrágios e acidentes na atividade da pesca artesanal.

Palavras-chave: Capacitação.Cultura.Navegação.Pesca.Artesanal.Segurança.

\section{EXTENSION PROJECT ABOUT THE SAFETY OF NAVIGATION AND PREVENTION OF ACCIDENTS IN FISHING CRAFT}

\begin{abstract}
The fishing conditions in Brazil is limited by the lack of expansion of public policy, acting in a few kilometers from the coast with few resources and great navigational risks of accidents. The fishing is practiced by professional fisherman directly, autonomously or in a household system, with means of production own or through partnership contract, using small vessels. The risks that affect traditional fishers are from different areas, including by overwork, especially natural hazards, chemical and physical, are subject to sea conditions and vessel. For
\end{abstract}


these reasons, the AQUASEG Centre of Federal University of Santa Catarina promotes training in the area of compliance of safety of navigation and the application of knowledge of new technologies to prevent accidents and shipwrecks in the activity of traditional fishing.

Keywords: Training. Culture.Navigation. Fishing. Safety. 


\section{INTRODUÇÃOO}

Conceituada como pesca "artesanal" ou "tradicional", esta atividade de pesca se desenvolve e se mantém exclusivamente pelo trabalho manufatureiro do pescador, com a participação dos pescadores tripulantes e de pessoas em terra, todos estando presentes nas etapas preparatórias, de apoio para navegação, de retirada do pescado, de armazenagem e de comércio. Tendo como resultado a obtenção de lucro pelo produto pescado e depois comercializado, em parte pode ser considerada também como item de lucro a parte do pescado que é consumida em rateio feito pelos próprios produtores.

A pesca artesanal está fundada nos conhecimentos dos antepassados que são transmitidos ao pescador, através das gerações, pela tradição e efetivada pela interação com os companheiros do ofício. Sempre realizada em pequenas embarcações (botes, canoas e baleeiras) a remo ou a vela, ou mesmo motorizada, a pesca, geralmente, é feita sem instrumentos de apoio à navegação e equipamentos obrigatórios. Desta maneira, a tripulação trabalha apenas com a experiência e conhecimento rudimentar, como, por exemplo, a capacidade de observação climática sobre os ventos, as ondas, marés e cardumes, também, tendo poucos conhecimentos sobre a embarcação.

De fato, há uma relação muito próxima entre a economia de subsistência e a pesca artesanal, o que torna dificultosa a percepção das autoridades públicas acerca da linha tênue que separa a pesca artesanal da pesca industrial. A maioria da população litorânea e ribeirinha é composta por inúmeras categorias de pescadores e, muitas vezes, um mesmo pescador tem um pequeno negócio familiar para pesca artesanal e também embarca como empregado ou autônomo na pesca industrial.

A produção do Brasil atualmente é de 1,2 milhões de toneladas de pescado, sendo que $70 \%$ são provenientes da pesca artesanal. Defende-se que a capacidade de produção ideal seria de 20 milhões de toneladas de pescado por ano. A matriz pesqueira é deficitária e está sucateada, sendo aos poucos abandonada culturalmente.

Assim, diante de tantos fatores possíveis para uma atividade de extensão, foi priorizado como objetivo principal o estudo das normas sobre segurança da navegação e a verificação dela em relação aos riscos de acidentes e naufrágios na atividade laboral de pescadores na atividade de pesca artesanal. Como objetivos acessórios têm os seguintes itens a se verificar: as soluções jurídicas e socioeconômicas, a começar pela própria realização da 
extensão universitária com efeito educativo, cultural, técnico e acadêmico e a expansão da atividade de maricultura e aquicultura, intentando-se com isso primar pelo desenvolvimento da nação em consonância com a sustentabilidade na atividade pesqueira.

\section{Construindo uma cultura da segurança da navegação.}

As ações típicas de extensão universitária, que são ouvir e transmitir informações em determinado segmento da sociedade, foram elaboradas como duas estratégias, tidas como principais e acessórias, começando pela primeira que foi a construção de instrumentos de intervenção para educar, com objetivo de estimular o debate e ouvir os pontos de vista dos pescadores sobre a navegação segura na pesca artesanal. Depois, a segunda estratégia foi a idealização de um produto audiovisual, o "Curso do Pescador Seguro" e, em conjunto, houve a elaboração de um texto básico de conhecimentos sobre a segurança da navegação na pesca artesanal, chamado de "Cartilha do Pescador Seguro", que contém linguagem facilmente compreendida pelo público-alvo.

Paralelamente, destaca-se a construção, hospedagem e manutenção de site na internet contendo todos os conteúdos acima e as ações estratégicas acessórias de interlocução tecnológica e social, com a finalidade de estimular uma cultura de segurança da navegação nos seus amplos aspectos: legais, de direitos e obrigações, como a legislação federal e as funções de órgãos públicos que atuam nesta atividade econômica e outros assuntos sobre segurança da navegação envolvendo novas tecnologias que alcançam equipamentos e formação de pescadores.

Em consonância com o exposto acima, ressalta-se a importância do ensino de direitos e obrigações, nas questões envolvendo a atividade econômica da pesca, que se habilita através da conscientização jurídica dos pescadores artesanais sobre normas do Direito Aquaviário e outras de importância profissional, como as relativas ao relacionamento com as autoridades públicas, citando-as, a Marinha do Brasil, o Ministério da Pesca e Aquicultura, a Previdência Social, o Ministério do Trabalho e Emprego e os órgãos de fiscalização ambiental.

Do ponto de vista operacional, tem-se a verificação de aspectos técnicos, como embarcações seguras e equipamentos de navegação obrigatórios, discussão sobre uma possível solução socioeconômica para aquisição destes, pelos pescadores artesanais.

Mais efetivamente, busca-se a construção de um modelo de desenvolvimento sustentável com a devida proteção ao meio ambiente, temas que são eixos transversais em 
cada assunto, especificamente, sobre a pesca artesanal e uma produção com menor risco de acidentes, tanto para o pescador quanto para o meio ambiente. E, de forma justa, criar um centro de cultura tradicional da pesca, tendo sua história preservada e atividades como museu da pesca artesanal.

Esclarecendo o assunto sobre os produtos que formam os principais objetos de ensino. A Cartilha do Pescador Seguro e o Curso do Pescador Seguro, pode-se dizer que são as duas produções informativas feitas para valorização da profissão tradicional que vem se sustentando na pesca artesanal e que é feita perto das praias e que utiliza redes de cerco, em barco a remo ou em pequenas embarcações, com propulsão de motor simples movido a diesel. Estes pescadores contam com sua própria força de trabalho, de seus familiares e amigos para manter uma renda digna para viverem. Geralmente, este tipo de pesca depende de condições climáticas favoráveis e de um esforço concentrado em determinadas épocas do ano.

A Cartilha do Pescador Seguro é um texto com imagens que tem informações resumidas e básicas para os pescadores profissionais e foi impressa em material à prova d'água, para poder ser levada a bordo do barco de pesca e ter mais durabilidade e resistência.

O audiovisual chamado de Curso do Pescador Seguro foi produzido a partir de conceitos profissionalizantes, trazendo informação de como se tornar um pescador profissional artesanal, como ser um aquaviário habilitado pela Marinha do Brasil e como ter um registro de pesca junto ao Ministério da Pesca e Aquicultura. No conjunto, são transmitidos os valores sociais positivos de buscar as licenças e os meios legais para o regular exercício profissional. Além disso, são explicadas as obrigações e direitos, principalmente, os trabalhistas e previdenciários, o compromisso com a salvaguarda da vida humana no mar e o respeito pelo meio ambiente. Estes e outros pontos são abordados no vídeo, em sintonia com a marcante presença de depoimentos dos pescadores, que participaram das gravações e colaboraram para a produção do objeto de ensino, e das entrevistas com as autoridades públicas, como Capitão dos Portos, o representante do Ministério da Pesca e Aquicultura (MPA), os especialistas e os docentes que foram fundamentais para os esclarecimentos. Tudo isto faz do Curso do Pescador Seguro um marco inicial de uma extensão universitária pertinente ao ambiente ilhéu de Florianópolis e da sua vocação econômica para a pesca.

Ambos os objetos de ensino encontram-se disponíveis no site do Laboratório de Estudos em Direito Aquaviário e Ciência da Navegação. Tal medida de tecnologia de ensino à distância, pode ser incentivada nas atividades de extensão e serve para tornar mais abrangente as consultas pela rede digital e aumentar o seu acesso pelos interessados. 
Contando com dois anos do edital que permitiu o seu desenvolvimento, pode-se contar a trajetória do projeto de extensão que, em 2011, teve seu trabalho levado ao $29^{\circ}$. Seminário de Extensão das Universidades da Região Sul (SEURS), quando foi possível disseminar a importância da segurança da navegação, tanto para outras universidades quanto para os alunos de escola de ensino médio em Foz do Iguaçu, onde o Rio Paraná é bastante navegado e, também, se faz a pesca artesanal, no evento realizamos uma oficina de extensão.

Destacam-se mais alguns momentos em que a atividade de extensão chegou ao público-alvo. Nos "Portões Abertos", em 2011, que é um evento anual realizado pela Base Aérea de Florianópolis, que congrega toda comunidade ilhéu e da sua região metropolitana, o nosso estande foi visitado por centenas de pessoas. Os alunos bolsistas estiveram lá para levar o conhecimento para a comunidade visitante que prestigiava o evento.

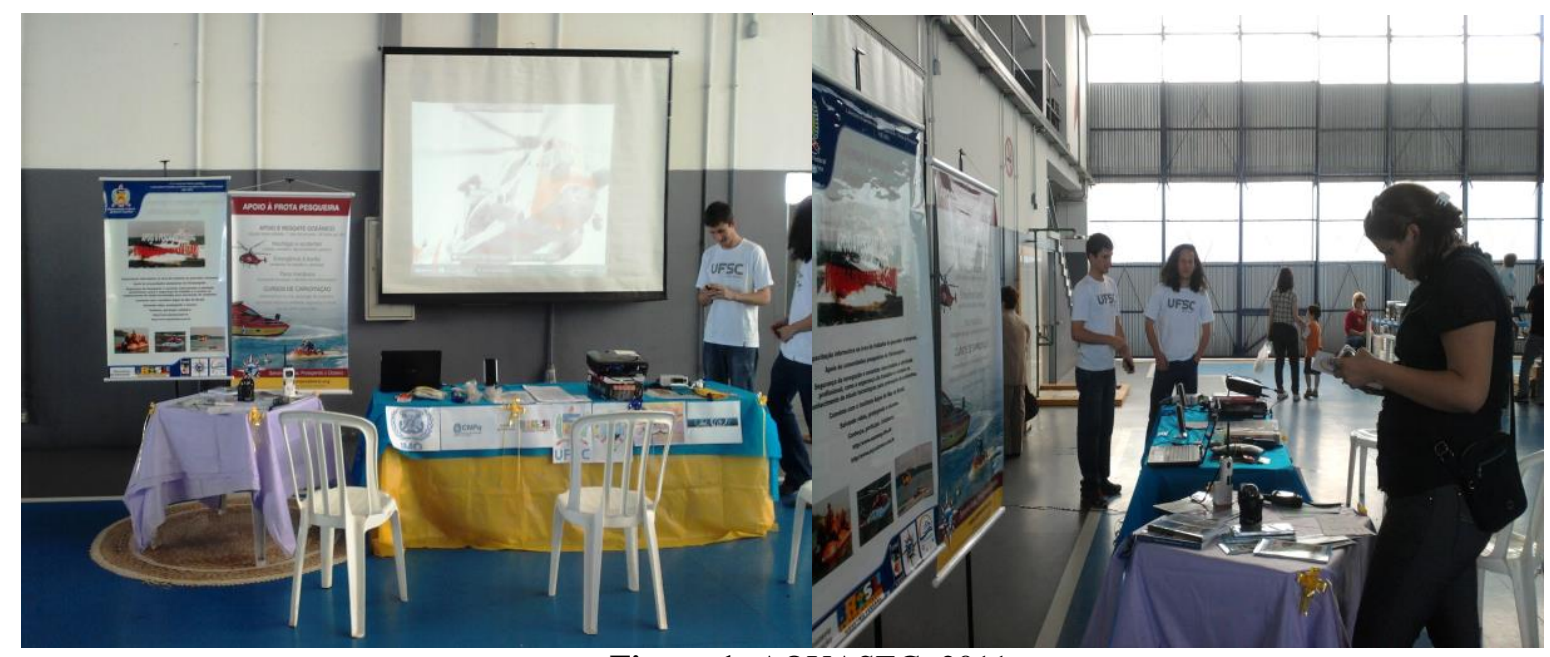

Figura 1: AQUASEG, 2011

Fonte: Elaborado pelos autores.

Em mais um momento marcante da extensão universitária, depois da época da pesca que se estende entre os meses de inverno e primavera, quando os pescadores artesanais estão bem ocupados, então, somente no início do verão, em dezembro de 2011, o AQUASEG foi convidado e participou da festa de confraternização de natal da comunidade de pescadores artesanais com barcos a remo, localizada na Praia do Campeche. Naquela oportunidade foi feita a divulgação do material didático e da pesquisa sobre a pesca artesanal. A programação do evento contou com orquestra dos músicos locais, almoço com autoridades, amigo secreto, exibição de um filme de surfe e uma breve apresentação do audiovisual Curso do Pescador Seguro. Em evidência na comunidade ilhéu de Florianópolis, o pescador "Seu Getúlio" tem 
uma associação que preserva os valores da pesca artesanal e faz mais do que isso, ele é o maestro de uma banda de música que ensaia e se apresenta no rancho de pesca.

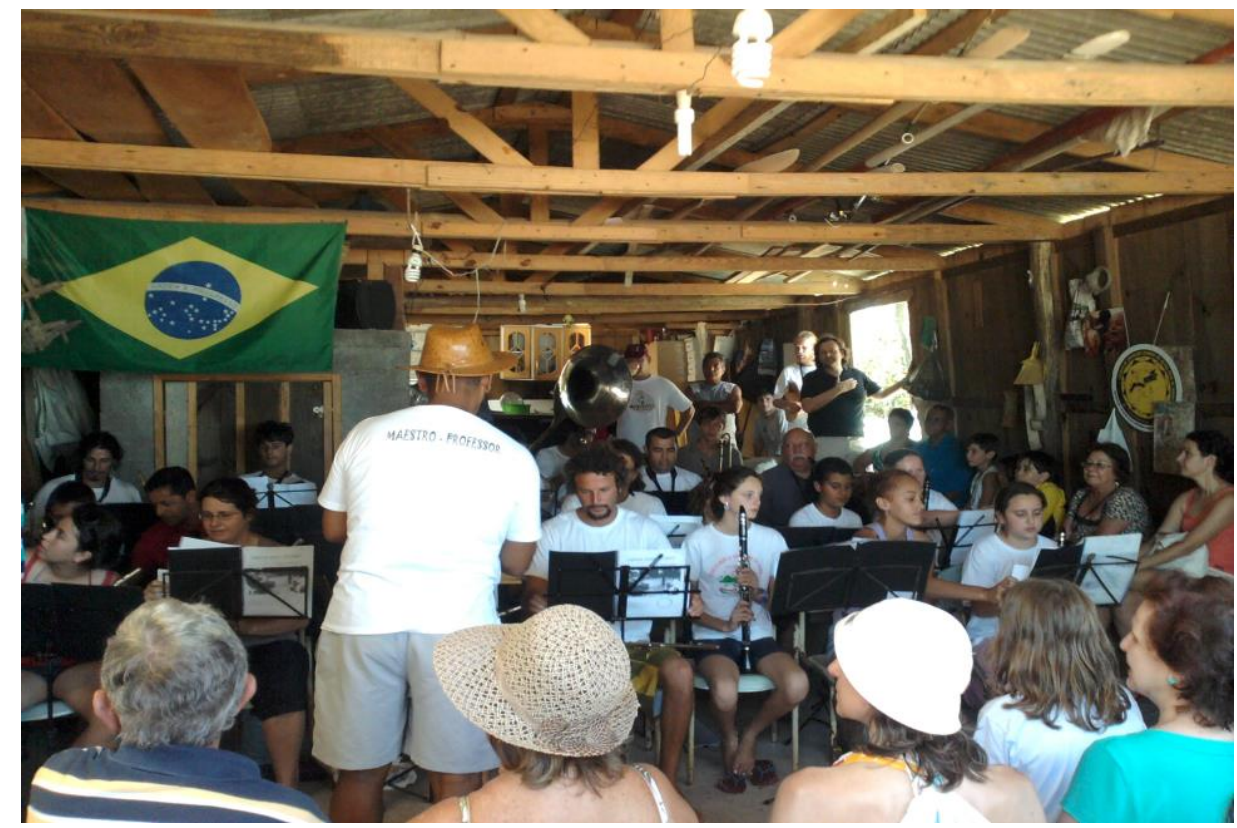

Figura 2: AQUASEG, 2011

Fonte: Elaborado pelos autores.

No 30. SEURS, em 2012, continua a campanha do AQUASEG pela conscientização sobre a segurança da navegação e a nossa equipe foi ao encontro de estudantes do ensino fundamental na região pesqueira para difundir a cultura da salvaguarda da vida humana no mar e para falar sobre as profissões que se envolvem na busca e resgate e segurança da navegação. Muitos dos adolescentes que participaram da oficina são filhos de pescadores, de aquaviários e de portuários, eles puderam interagir contando suas experiências e, também, assistirem uma atividade prática que foi o lançamento de dispositivo pirotécnico sinalizador de localização por fumaça laranja, adotado como sinal internacional de localização em casos de perigo no mar.

Enfim, tudo o que está sendo realizado sinaliza para um eficiente resultado do PROEXT do Edital nº. 5/2010 do MEC/SESU, o qual permitiu a implantação do projeto de extensão tão relevante para sociedade brasileira. Atualmente, o projeto se mantém com recursos da própria universidade, permitindo a continuidade das suas atividades, pela importância destas para a zona costeira de Santa Catarina.

Assim, com os merecidos reconhecimentos sociocultural e acadêmico, o AQUASEG participou de cerimônia política em abril de 2012 do "Ato de Entrega de Cessão de Áreas 
Públicas em Águas da União para o Desenvolvimento da Maricultura no Estado e de Autorizações de Pesca Complementar para Captura de Tainha e Abertura do Encontro de Planejamento de Integração Regional da Piscicultura", na Assembleia Legislativa do Estado de Santa Catarina. Na ocasião, o Ministro da Pesca, Marcelo Crivella, em pronunciamento, enfatizou a importância de instrumentos de educação e capacitação para comunidades de pescadores artesanais de Santa Catarina e de todo o país. Ao final da cerimônia a Coordenação do AQUASEG, entregou ao Ministro o DVD do Curso do Pescador Seguro, informando-o da existência de uma parceria entre a UFSC e o MPA, que ajudou na criação do material didático para o setor da pesca artesanal e que foi feito com os recursos do PROEXT.

Ainda, no primeiro semestre de 2012, aconteceu o VI Ciclo de Debates sobre a Segurança da Navegação, o qual já é um evento com seis anos de tradição no Curso de Graduação em Direito.

E, também, foram organizados e ministrados dois cursos de capacitação para tripulação e condução de embarcação de Estado para servidores públicos, ambos em conjunto com a Marinha do Brasil.

De fato, acontece uma boa receptividade de todos que estão envolvidos em atividades relacionadas à navegação, por este motivo o AQUASEG está crescendo e permitindo que outras demandas sejam trazidas, debatidas, pesquisadas e transformadas em atividades de extensão. A integração entre o ensino, a pesquisa e a extensão e a questão multidisciplinar que envolve a navegação em meio aquaviário. Importante para os alunos da Graduação em Direito foi trabalhar com os aspectos da legislação federal que dispõe sobre segurança da navegação, sobre o registro de pesca, sobre a segurança do trabalho e sobre a previdência social dos pescadores. A pesquisa destas fontes legais foi direcionada para conscientização jurídica dos pescadores artesanais sobre normas do Direito, de como funcionam na realidade e na prática. Mas, interdisciplinarmente, o projeto também contou com a participação de uma aluna do Curso de Graduação em Oceanografia, que trabalhou os aspectos socioambientais.

Com cinco bolsas de extensão no ano de 2011 e uma em 2012, mais a participação de voluntários e de técnico-administrativos e docentes da universidade, também, contando com o apoio da Fundação José Arthur Boiteux, foi possível atingir todas as metas previstas e viabilizar a continuidade do projeto de extensão. Por exemplo, os bolsistas puderam desenvolver objetos de ensino, como o que segue abaixo: 


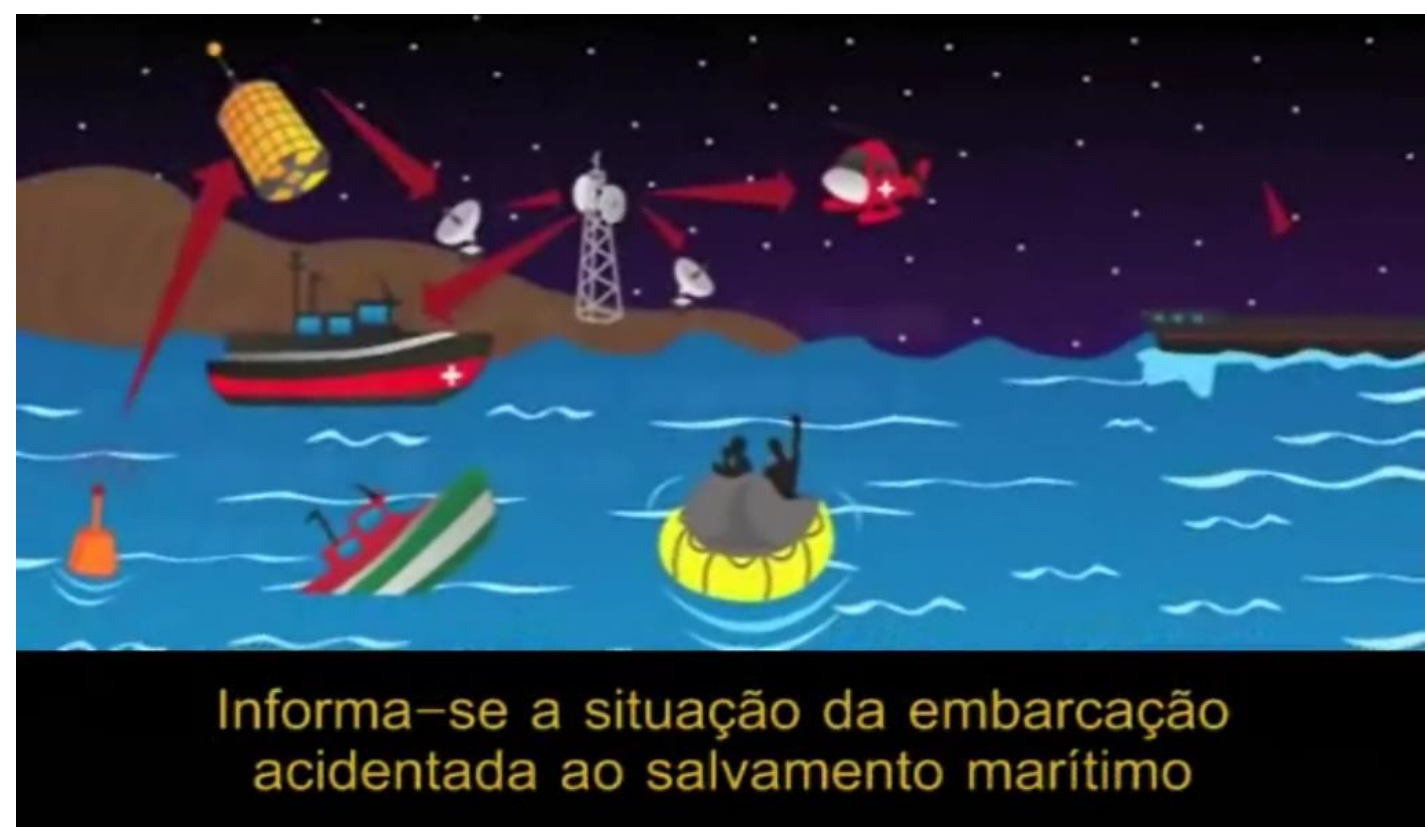

Figura 3: Imagem do vídeo instrucional Fonte: Elaborado pelos autores.

No Curso de Graduação em Direito, pode-se destacar que ocorreu uma pontual reforma curricular com uma nova proposta que aprovou uma disciplina optativa chamada de "Direito Aquaviário", ministrada pelo Coordenador do projeto. Assim, alguns dos bolsistas selecionados foram alunos, antes, durante ou depois da execução do projeto, tendo sido incluída a nova disciplina em seus currículos acadêmicos. Além de outros alunos do Direito e dos demais cursos que procuram o conhecimento nesta área.

Vale ressaltar uma dificuldade encontrada, no que diz respeito ao quesito bolsa de extensão, porque esta modalidade não é contemplada para estudantes de pós-graduação, em razão de não haver previsão de "rubrica de pagamento" pela nossa universidade. Tal incongruência foi comunicada de imediato para que se inclua futuramente e para que seja possível uma resolução deste impasse.

Em se tratando de ações de extensão deve-se primar pela integração dos níveis de ensino e pesquisa existentes e disponíveis também na pós-graduação, os quais ampliarão os estudos na área e melhor investigarão os aspectos didáticos e científicos que tangem a capacitação e habilidades técnico-científicas, principalmente, por se tratar de conhecimento formado por diversas áreas da ciência, de fato uma abertura multidisciplinar, um tanto complicada para aqueles que estão acostumados aos compartimentos fechados de áreas científicas, na navegação há uma racional amplitude de matérias diversas que permeiam os meios pelos quais se realiza as atividades em meio aquaviário. 


\section{CONSIDERAÇÕES FINAIS}

Concluindo, em poucas linhas, observa-se que um importante projeto de extensão universitária está sendo realizado, evidenciando-se que o AQUASEG, através das políticas públicas de fomento do Ministério da Educação e com recursos próprios da UFSC e parcerias corretas com as autoridades públicas envolvidas, alcançou o objetivo de desenvolver as atividades que se destinaram à comunidade de pescadores artesanais de Florianópolis.

Assim, constrói-se uma cultura de segurança da navegação (maritime safety), que foi idealizada no início do projeto e que se desenvolveu, ganhando vida própria, materializandose e se tornando uma útil e inteligível transmissão de informações relacionadas à atividade laboral dos pescadores artesanais no tocante à segurança do trabalho e aos direitos e deveres dela decorrentes.

Diga-se que tudo isso foi possível a partir da participação de alunos, docentes, técnicos administrativos e colaboradores externos, sendo eficiente e garantidora da realização dos trabalhos. E, como consequência, vem ocorrendo uma ótima receptividade das comunidades pesqueiras.

Do ponto de vista de uma cidadania pró-ativa, a existência do artigo 207 da Constituição da República garante que as universidades brasileiras tenham autonomia didático-científica, administrativa, de gestão financeira e patrimonial, que atentem ao princípio da indissociabilidade entre ensino, pesquisa e extensão. Foi por meio destes princípios fundamentais da atividade de extensão que se procedeu à difusão, socialização e democratização do conhecimento, assumindo a forma de prestação de serviços à comunidade de pescadores artesanais e, como ficou claro, vai continuar e até ampliar suas atividades para outros segmentos do meio aquaviário.

\section{REFERÊNCIAS}

ALVES, Maria Bernardete Martins.; ARRUDA, Susana Margareth. Citações em documento. Universidade Federal de Santa Catarina. [s.d]. Disponível em: http://www.bu.ufsc.br/design/Citacao1.htm. Acesso em 09 abr. 2009.

BRASIL. Constituição da República Federativa do Brasil. Lei $n^{\circ} .11 .959$ de 30 de junho de 2009. . Lei $n^{\circ} .9 .537$, de 11 de dezembro de 1997.

COSTA, Fábio Martins. COTRIM, Décio Souza. SANDER, Marcos Aurélio. A "Pesca do Bote" entre os pescadores profissionais artesanais do Litoral Norte do RS. Estudo do 
Escritório Municipal da Emater/RS. Escritório Regional de Porto Alegre, 2006. Disponível em: http://www.emater.tche.br/site/br/arquivos/area/frentes/4/pesca_bote.pdf. Acesso em: 19 jun. 2012.

COUTO. José Luiz Viana do. Riscos de acidentes na zona rural: riscos da pesca e aquicultura. Estudo da Universidade Federal Rural do Rio de Janeiro. Disponível em: http://www.ufrrj.br/institutos/it/de/acidentes/pesaq.htm. Acesso em: 19 jun. 2012.

LEBRE, Eduardo Antonio Temponi. O Direito Marítimo e os órgãos da autoridade marítima. Âmbito Jurídico, Rio Grande, n. 71. Disponível em: http://www.ambitojuridico.com.br/site/index.php?n_link=revista_artigos_leitura\&artigo_id=6 992. Acesso em: 19 jun. 2012.

; ULYSSEA, Marcelo Assumpção; SELAU, Cássio Brognoli. A estrutura brasileira do Serviço de Busca e Salvamento. Anais do $29^{\circ}$ SEURS - Seminário de Extensão Universitária da Região Sul, Foz do Iguaçu, PR. Disponível em: http://www.aquaseg.ufsc.br/files/2011/06/A-estrutura-brasileira-do-Serviço-de-Busca-eSalvamento.pdf. Acesso em: Acesso 19/06/2012. 